\title{
EVOLUÇÃO DO BALANÇO SOCIAL NA ADMINISTRAÇÃo PÚBLICA ITALIANA
}

\author{
SOCIAL REPORTING EVOLUTION IN ITALIAN PUBLIC ADMINISTRATION
}

\author{
Vincenzo Criscuolo \\ Universidade de Napoli - Italia
}

\section{RESUMO}

Este trabalho fornece informações sobre os relatórios sociais na administração pública italiana, evidenciando elementos descritivos e críticos para uma comparação entre experiências de diferentes países e que sirvam de estímulo para futuras análises. A crescente demanda por accountability e a implementação, na Itália, como no resto da Europa, de um profundo processo de reforma da administração pública alimentaram, nos últimos anos, o desenvolvimento de novos relatórios pelas entidades públicas de vários níveis institucionais. O Balanço Social nasce como um instrumento de medida da Responsabilidade Social e de comunicação das informações não necessariamente econômicas, mas principalmente sociais e ambientais. O paper analisa criticamente, em termos comparativos, as regras de redação do balanço social pelas administrações públicas (APs), propondo e estabelecendo os dois principais padrões já existentes na Itália: o Grupo de Estudo sobre o Balanço Social $(G B S)$, que, em 2005, produziu um standard aplicável para todas as APs, e o Observatório das Finanças e Contabilidade das Entidades Locais, que publicou, em 2007, as diretrizes chamadas na Itália "Linhas Guia" para os relatórios sociais nas entidades locais. A comparação evidencia uma ampla área comum, mas também algumas diferenças significativas. A segunda parte do trabalho oferece algumas evidências empíricas, em particular o documento que foca a realidade de uma província italiana específica. A combinação entre as análises dos conteúdos dos standards e as evidências empíricas evidencia algumas áreas críticas para os relatórios sociais no contexto das APs italianas, para as quais deve-se endereçar os futuros aprofundamentos teóricos e as experimentações operacionais.

Palavras-chave: Informação. Comunicação. Impacto social. Responsabilidade social.

\begin{abstract}
This paper aims to provide a full update about social reporting of the Italian public administration, pointing out some descriptive and critical elements, necessary for a comparison among various countries which are needed for future comparative analysis. A growing demand of accountability and success both in Italy and Europe of a reform process in public administration, in recent years, helped the development of new reporting instruments in public entities of different levels. Social reporting was born as an instrument to measure social and environmental information of communication and social responsibility. The paper analyzes the editor social reporting roles in public administration in a critical and comparative form. It also suggests two principal standards already existing in Italy: the $G B S$ that in 2005 produced an applicable standard for all public administration and the osservatorio della finanza e contabilità degli enti locali that in 2007 published the linee guida (guide lines) for social reporting local entities. The comparison highlights a big common area and also meaningful differences. In the second part of this paper some empirical evidences are shown. In particular, we are going to talk about the case of an Italian province. The crossing between standard contents analysis and empirical evidences point out some critical areas for social reporting in the context of the Italian public administration, towards which we can address the future theoretical and operative studies.
\end{abstract}

Keywords: Information. Communication. Social impact. Social responsibility. 


\section{INTRODUÇÃO: O SOCIAL REPORTING NA ADMINISTRAÇÃO PÚBLICA.}

A evolução da prática do relatório social, na Itália, tinha um curso parecido ao dos outros países. O primeiro caso de balanço social de uma empresa ocorre no final dos anos 70, mas só na segunda metade dos anos 90 o fenômeno tomou uma dimensão apreciável. Cabe destacar que os temas éticos e de responsabilidade social sempre foram pedras angulares da edificação da escola italiana das ciências contábeis e da "economia aziendale" (Zappa, 1957) (Masini, 1979) (Coda, 1988). É significativo que, se no mundo anglo-saxônico o balanço social teve seu desenvolvimento ligado à afirmação do paradigma da Corporate Social Responsibility (CRS), na Itália, esse relatório difunde-se primeiramente nas empresas públicas e no mundo cooperativo e associativo (Viviani, 1999). Os primeiros balanços sociais foram elaborados pelas ferrovias estatais nos anos 90.

No campo da administração púbica, a primeira tentativa de redação de balanço social foi no ano 1998. A administração pública italiana aparece, portanto, temporariamente, alinhada ao mundo das empresas e as experiências dos outros países europeus.

Os elementos que dirigem a administração pública italiana para adoção do social reporting são particulares: eles não são nem a orientação pela CRS, nem a exigência primeira de captar recursos financeiros - como no caso das "entidades sem fins lucrativos privadas" (Hinna, 2004).

Em primeiro lugar, a responsabilidade social é interpretada de maneira diferente das empresas comerciais, bem como das entidades sem fins lucrativos, sejam essas últimas públicas ou privadas. Se nas primeiras este conceito é interpretado como um "vínculo ao ordinário fim econômico", nas entidades sem fins lucrativos, agentes econômicos que, por definição e vocação, vivem a responsabilidade social como a sua "missão" (Matacena, 1984), o paradigma é invertido: a responsabilidade social é o elemento propulsor da atividade institucional, não uma opção ética, mas um "dever".

Em segundo lugar, as motivações da difusão do social reporting no setor público ligam-se a fatores ambientais e ao consequente processo de reforma da administração pública que, na Itália, vai começar nos primeiros anos da década de 90. Tais motivações muitas vezes vêm identificadas como o processo de "aziendalizzazione" da púbica administração (Anselmi, 1995) (Valotti, 2000).

Entre os variados aspectos das mudanças, alguns elementos tomam grande relevância interpretativa na evolução dos sistemas informativos da administração pública (D'Amore, 2008):
a. Reforço e amplificação do conceito de accountability;
b. Passagem dos modelos de public government aos modelos de public governance;
c. Inadequação das demonstrações contábeis tradicionais.

A evolução do conceito de accountiability acarreta a passagem de um relatório que pretende demonstrar o uso legítimo dos recursos (no sentido jurídico - formal) para um relatório sobre o uso eficiente e, principalmente, eficaz dos recursos.

Portanto, o sistema de informação pode evidenciar a contribuição e o bem-estar social, ou seja, o impacto da gestão pública no território de referência, através da relação entre os recursos consumidos e produzidos. Em outros termos, "o valor público criado" para os diferentes interessados (Moore. M, 1995) (Borgonovi, 2000). Podemos deduzir, portanto, a inadequação dos relatórios contábeis tradicionais para satisfazer os novos requisitos de accoutability. 
Nasce, então, a exigência de apoiar estes relatórios tradicionais numa documentação apta para dimensionar o impacto da entidade pública sobre os diferentes stakeholders. O balanço social tem, principalmente, que transmitir, de maneira transparente e controlável, as informações de impacto social e divulgá-las aos diferentes interessados, ou seja, aqueles sujeitos (indivíduos ou grupos) que têm um interesse legítimo nas atividades das entidades, não necessariamente econômico, e que sem os tais suportes, em termos de recursos e contribuições, à organização deixaria de existir. Na entidade local. a ativação de um eficaz controle democrático pelos interessados pressupõe um sistema de relatórios capaz de representar de maneira simples e transparente os resultados da gestão. A complexidade dos princípios contábeis e o tecnicismo léxico tinham sido, historicamente, as causas do desalinhamento informativo entre oferta e demanda das informações, considerando que eram destinadas para um público variado. "0 cidadão-usuário tem que ser capaz de avaliar a qualidade das alternativas de serviços existentes, caso se queira que as suas escolhas sejam conscientes" (Marcon, 2008). Ele tem que ser posto na condição de avaliar os programas eleitorais e as sucessivas realizações. Da mesma maneira, os outros interlocutores sociais têm que poder avaliar a relação entre as contribuições oferecidAs e as recompensas auferidas. A accountability é inerente à ideia de democracia dos stakeholders.

Neste sentido, o balanço social desempenha um papel de consolidação da comunicação, apoiando os demais relatórios contábeis e tentando evidenciar o conteúdo das relações que se instauram entre instituto e meio ambiente.

Além disso, nos últimos anos, o balanço social está adquirindo uma importância crescente tambèm como instrumento de geração e conservação do consenso sobre o projeto e a estratégia. O balanço social e os outros instrumentos de social reporting não só se propõem ao papel de comunicar e informar aos stakeholders, mas também a atingir o objetivo do envolvê-los nas políticas e estratégias da entidade e no controle sobre a implementação das mesmas. 0 social reporting toma uma função estratégica ex ante, como base para o envolvimento dos stakeholders, e ex post, como base para uma medição da coerência entre o previsto e o realizado.

Em fim, o processo de informação favorece a definição de padrões de referência para a avaliação das prestações de contas internas e constitui um mecanismo de coordenação utilizado pelas administrações locais para favorecer e potencializar as relações com os agentes externos, titulares de funções e serviços públicos. Neste sentido, accountability, controle estratégico e balanço social são ligados por vínculos de "instrumentalidade" e função recíproca, no âmbito do novo modelo de governance pública.

\section{O DESENVOLVIMENTO DAS PRÁTICAS E DOS PADRÕES PARA O BALANÇO SOCIAL NA ADMINISTRAÇÃO PÚBLICA ITALIANA}

No último decênio, assistiu-se ao desenvolvimento voluntário de formas de comunicação social pelas administrações públicas (AP) ${ }^{1}$ italianas. Embora muitas normas, a partir dos anos 1990, tenham enfatizado e acrescido os requisitos de transparência e de accountability nas AP, até 2006 registrou-se a ausência de regras específicas relacionadas ao balanço social.

\footnotetext{
${ }^{1}$ A República Italiana é um Estado fundado sobre o modelo regional, que nos últimos anos conheceu um crescente requerimento pela devolução dos poderes e pela descentralização administrativa . Para a Constituição Italiana, "A República é constituída pelas câmaras municipais, províncias, cidades metropolitanas, regiões e Estado.

As câmaras municipais, as províncias, as cidades metropolitanas e as regiões são entidades autônomas com estatutos próprios, poderes e funções para os princípios fixados pela Constituição (art.114). 0 poder de legislar é praticado pelo Estado e pelas regiões (art.117). As funções administrativas são atribuições das câmaras municipais e, só em alguns casos, para assegurar o exercício unitário, elas sã atribuídas às províncias , cidades metropolitanas , regiões e Estado, pelo princípio da "subsidiariedade" (art.118).
} 
A redação do balanço social, no contexto da administração pública italiana, constitui, portanto, o êxito das experimentações realizadas pelas entidades, no âmbito da própria autonomia estadual e regulamentar. As experiências amadurecidas pelas entidades de vários níveis institucionais e com diferentes funções acarretaram a difusão de documentos diferentes na denominação, finalidade e conteúdos: balanço social, balanço de termo (missão), balanço socioambiental, balanço de gênero, balanço de sustentabilidade, balanço participativo, etc.

Tabela 1: Difusão dos vários instrumentos de relatório social distribuídos pelas áreas territoriais ${ }^{2}$

\begin{tabular}{|l|c|c|c|c|c|}
\hline & B. Social & $\begin{array}{c}\text { B. } \\
\text { Ambiental }\end{array}$ & $\begin{array}{c}\text { B. de termo } \\
\text { (missão) }\end{array}$ & $\begin{array}{c}\text { B. } \\
\text { participativo }\end{array}$ & B. de gênero \\
\hline Províncias/109 & 20 & 4 & 17 & 1 & 2 \\
\hline Câmaras municipais/ 8101 & 107 & 17 & 42 & 3 & 6 \\
\hline Regiões/20 & 1 & 0 & 2 & 0 & 0 \\
\hline
\end{tabular}

Como podemos perceber na tabela 1 , as técnicas do social reporting na Itália são ainda pouco difundidas. 0 balanço social constitui o instrumento relativamente mais utilizado, seguido pelo balanço de termo. Aponta-se as "entidades locais" (províncias e câmaras municipais,) como as que mostram uma maior propensão ao uso de formas de relatório social, comparadas às entidades sobre-ordenadas (regiões). Pode-se dizer, então, que as entidades às quais a lei atribui funções administrativas, responsáveis, portanto, pela prestação dos serviços aos cidadãos, reconheçam mormente a exigência de comunicar informações sobre a dimensão social das suas atividades.

Para alguns importantes estudiosos, "A crescente difusão do balanço social nas entidades locais representa, ao menos em parte, uma tentativa de resposta à falta de ordenamento financeiro e contábil, em matéria de comunicação e programação." (Pozzoli, 2006).

0 processo de proliferação dos instrumentos e das linguagens de comunicação voluntária, entre administração e stakeholders, fez surgir uma forte demanda pela padronização para garantir a efetividade e compreensibilidade, mas também a comparabilidade espaço-temporal, das informações produzidas pelas AP.

Com atenção especial ao balanço social, uma primeira intervenção foi registrada em 2005 pelo Grupo de Estudo sobre balanço social (GBS), uma associação privada, nascida em 1998, com a finalidade de elaborar princípios uniformes para a redação do balanço social e que prevê a participação de pesquisadores, aconselhadores e representantes do setor público. 0 primeiro documento produzido pelo grupo, em 2001, delineia o perfil geral do balanço social, com referência especial às empresas ${ }^{3}$. 0 GBS estendeu este modelo às administrações públicas, emanando a primeira norma sobre o balanço social para o setor público na Itália.

Em 2006, o Departamento da Função Pública da Presidência do Conselho dos Ministros emanou uma "diretiva" sobre o relatório social nas administrações públicas através da elaboração do

\footnotetext{
2 Banco de dados sobre o balanço social previsto no FORMEZ para atender ao objetivo de difundir a cultura e a prática do balanço social. A iniciativa representa um dos resultados do projeto "Ação de Sustentabilidade" implementação do balanço social nas administrações púbicas.

${ }^{3}$ Documenti de Standard - Standard de adaptação, Documento n.1, "La Rendicontazione Sociale nel Settore Pubblico", Milano, 2005. 
balanço social, endereçada à totalidade das $\mathrm{AP}^{4}$. Trata-se de uma norma que, juntamente com uma recomendação para a adoção do balanço social pelas AP, contém a explicitação dos objetivos e dos pressupostos da elaboração do relatório e algumas indicações operacionais para a sua elaboração.

Em 2007, o Observatório de Finanças e Contabilidade das entidades locais, instituído no Ministério dos Assuntos Internos, emanou orientações mais pormenorizadas para a redação dos relatórios sociais ${ }^{5}$ chamadas na Italia "Linhas Guia". Neste caso, as indicações também não são integradas e só são aplicáveis às entidades locais (províncias, câmaras municipais, comunidades montanhosas e cidades metropolitanas).

\section{Modelos de balanço social nos padrões italianos: uma comparação}

O documento do GBS e as diretrizes do Observatório constituem, portanto, os padrões de referência suficientemente articuladas e que permitem uma primeira comparação interessante entre os modelos de relatório que vão se consolidando na administração pública italiana.

As duas fontes preocupam-se em definir, antes de tudo, a estrutura do balanço social, articulada em capítulos ou em partes principais, conforme tabela 2. Como se pode observar as estruturas sugeridas apresentam vários pontos em comum, mas também algumas peculiaridades sobre as quais é oportuno destacar.

As duas entidades regulamentadoras prevêem que o balanço social deve ser precedido por uma "apresentação" (ou "nota introdutória") com uma "nota metodológica". Os papéis desta parte introdutória são multíplices: a) fornecer uma sintética apresentação do balanço por parte da administração superior, compreensiva das motivações e finalidades do processo do relatório e do empenho da administração para dar continuidade à mesma; b) indicar os padrões de referência ou os princípios adotados; c) descrever o processo do relatório de maneira a fornecer uma guia à leitura e explicitar os aspectos processuais e metodológicos.

Nas Linhas Guia para as entidades locais, são enfatizados os aspectos de seleção e de consulta dos interessados envolvidos.

Tabela 2: Os conteúdos do balanço social: comparação entre os modelos do GBS e do Observatório

\begin{tabular}{|c|c|}
\hline STANDARD GBS & LINHAS GUIA OBSERVATÓRIO \\
\hline $\begin{array}{l}\text { Nota introdutória e metodológica } \\
\text { - Princípios utilizados ou padrões de referência. } \\
\text { - Processo de relatório }\end{array}$ & $\begin{array}{l}\text { Apresentação e nota metodológica } \\
\text { - Padrões de referência } \\
\text { - Período de relatório } \\
\text { - Coleta, elaboração e classificação dos } \\
\text { dados } \\
\text { - Grupo de trabalho } \\
\text { - Seleção e consultação dos stakeholder }\end{array}$ \\
\hline $\begin{array}{l}\text { Identidade } \\
\text { - Cenário e contexto econômico-social e operacional de } \\
\text { referência. } \\
\text { - Sistema de referência e ordem }\end{array}$ & $\begin{array}{l}\text { Identidade } \\
\text { - Dados sócio-econômicos } \\
\text { - Estrutura político-administrativa e }\end{array}$ \\
\hline
\end{tabular}

\footnotetext{
4 "Direttiva del Ministro delle Funzione Pubblica sulla rendicontazione sociale nelle amministrazioni pubbliche", DM.16/02/2006.
}

5 "Linee guida per la rendicontazione sociale negli enti locali", Roma, 2007. 


\begin{tabular}{|c|c|}
\hline $\begin{array}{l}\text { organizacionalPrincípios-guias, valores, missão/ões } \\
\text { - Estratégias e políticas }\end{array}$ & $\begin{array}{l}\text { organizacional } \\
\text { - Governance e políticos nos recursos } \\
\text { - Visão e missão } \\
\text { - Valores de referência } \\
\text { - Macroáreas de intervenção } \\
\text { - Grupo público local } \\
\text { - Stakeholders }\end{array}$ \\
\hline $\begin{array}{l}\text { Reclassificação dos dados contábeis e cálculos do valor } \\
\text { adicionado } \\
\text { - Valor adicionado global } \\
\text { - Valor adicionado por áreas de intervenção } \\
\text { - Distribuição do Valor adicionado global } \\
\text { - Patrimônio, e outros bens e empenhos } \\
\text { - Entradas e saídas por áreas de intervenção }\end{array}$ & $\begin{array}{l}\text { Recursos econômico-financeiros e dotação patrimonial } \\
\text { - Entidade e proveniência dos recursos financeiros à } \\
\text { disposição no período (também externas ao balanço) } \\
\text { - Equilibros e resultados financeiros de balanço } \\
\text { - Distribuição da despesa por macroáreas de } \\
\text { intervenção } \\
\text { - Proventos, custos, indicadores de equilíbrio } \\
\text { econômico } \\
\text { - Contribuição das macroáreas para o resultado } \\
\text { econômico compressivo } \\
\text { - Dotação patrimonial }\end{array}$ \\
\hline $\begin{array}{l}\text { Relação social } \\
\text { - áreas de intervenção e stakeholders } \\
\text { - Recursos utilizados } \\
\text { - Resultados obtidos } \\
\text { - Avaliação dos stakeholders }\end{array}$ & $\begin{array}{l}\text { Serviços (macro de intervenção) } \\
\text { - Documentação das programações } \\
\text { - Situação inicial } \\
\text { - Stakeholders específicos } \\
\text { - Finalidade, objetivos e recursos } \\
\text { - Resultados (output) e efeitos (outcome) } \\
\text { - Avaliação dos stakeholders } \\
\text { - Empenhos e ações futuros }\end{array}$ \\
\hline \multirow[t]{2}{*}{$\begin{array}{l}\text { Declarações } \\
\text { - Melhoria dos efeitos das atividades } \\
\text { - Melhoria do processo dos relatórios }\end{array}$} & \\
\hline & $\begin{array}{l}\text { Asseveração } \\
\text { - Relação do revisor } \\
\text { - Resultado da asseveração }\end{array}$ \\
\hline
\end{tabular}

\section{IDENTIDADE}

Constitui a primeira parte do balanço social pelas duas fontes examinadas. Os elementos considerados são, em grande parte, comuns.

Em primeiro lugar é necessário descrever o cenário e o contexto de referência da administração. Trata-se das características da comunidade administrada e do ambiente com as quais a alta administração lida (características sociais, econômicos, do ambiente físico, cultural, etc.). A apresentação do contexto em que a entidade atua ganha relevância específica, em termos da articulação territorial e de "âmbitos de intervenção", atuais e potenciais, objeto de exposição detalhada em parte subsequente do balanço.

Um segundo aspecto relevante está ligado à descrição dos órgãos de governance interna 
(natureza do termo, experiências profissionais, relações, emolumentos, etc.) e da estrutura organizacional (órgãos, papéis, responsabilidades, recursos, etc.).

Outra área fundamental é aquela da explicitação da "missão" e dos "valores" que guiam a administração ${ }^{6}$, os quais se encontram codificados nas normas de referência e nos documentos que expressam a autonomia da entidade (estatuto, regulamentos, códigos éticos etc.). As duas entidades enfatizam o requisito da "verificabilidade" da coerência entre missão e valores declarados no balanço social e conteúdos dos documentos programáticos nos quais se explicitam as escolhas da entidade. E também, o GBS exige os requisitos essenciais para assegurar a inteligibilidade dos valores: prescribilidade, observância, estabilidade, imparcialidade e universalidade.

A missão deve ser explicitada nas "estratégias" e "políticas". Também neste caso, o relatório deve fornecer os elementos necessários para verificar a coerência entre balanço social e outros documentos programáticos (plano geral de desenvolvimento da entidade, orçamento, balanço plurianual e anual etc.) nos quais se individualizam os projetos, as estratégias declaradas e atividades efetivamente desenvolvidas.

Elementos comuns inerentes às estratégias são: as áreas de intervenção, os stakeholders envolvidos, os objetivos perseguidos e os recursos utilizados.

As duas fontes examinadas exigem um esforço especifico na representação das políticas da entidade, mas com ênfases diferentes, ou seja: a) gestão dos recursos (políticas de recursos humanos, financeiros, balanço, aprovisionamentos, sistemas de informações etc.); b) gestão dos serviços (gestão direta/"externalização", descentralização etc.); c) governance externa ("partnership", organismos de participação, políticas de comunicação etc.); d) intervenção na esfera social, da economia local, de gestão territorial e ambiental7.

Uma área específica do relatório, segundo as linhas guia do Observatório Italiano, trata o "grupo público local", definido como "o complexo das entidades de direta emanação da entidade (empresas especiais, instituições, consórcios), das sociedades controladas, ligadas ou nas quais a entidade detém uma participação relevante". Relativamente a tais entidades econômicas, o documento prevê que sejam fornecidas algumas informações mínimas: setores de atuação, serviços "externalizados", resultados econômicos gerados, investimentos realizados e consistência das participações.

O GBS considera um delineamento que amplia as exigências do relatório. De fato "o balanço social deve relatar todas as atividades geridas diretamente pela entidade ou geridas por outras entidades sobre as quais a primeira tenha influência relevante (participações, contratos, concessões, acordos etc.). 0 balanço social deve ser reclamado ou recebido com avaliações, comentários ou interações, ao menos nos níveis de objetivos e estratégias, do público interno do balanço social da entidade. Por cada participação ocorre especificar: a abrangência, as modalidades, o conteúdo e duração".

\section{RELATÓRIO ECONÔMICO-FINANCEIRO}

Nesta parte observam-se as maiores diferenças entre as duas entidades regulamentadoras.

Constituindo a adaptação de um modelo de relatório originariamente elaborado pelas empresas privadas, o standard GBS, também no modelo predisposto pela AP, herda a característica do

\footnotetext{
${ }^{6}$ As diretrizes se distinguem da visão, pois aquelas são consideradas como o futuro perseguido pela administração e missão concebida como o propósito de fundo da entidade.
}

7 Estes últimos aspectos são destacados no documento GBS. 
cálculo do "valor adicionado" como instrumento apto a dar conta da riqueza produzida e distribuida às diferentes categorias de stakeholders. Na lógica proposta, e também se toma um significado peculiar nas empresas públicas, o valor adicionado é essencial pelas finalidades e a determinação do valor no relatório social (GBS, 2007). A utilidade do valor adicionado é justificada por dois aspectos:

- O laço que estabelece entra contabilidade econômico - patrimonial da administração pública e o relatório social;

- A funcionalidade da avaliação da eficiência adquirida no emprego dos recursos e da compreensão das modalidades da sua distribuição.

A representação do valor adicionado é obtida através a reclassificação dos dados contábeis em três diferentes perspectivas:

- Determinação do valor adicionado Global - reclassifica os valores da conta econômica da administração da qual se trata, de maneira a evidenciar o "valor adicionado característico", o "valor adicionado global bruto" e o "valor adicionado liquido global";

- Classificação do valor adicionado por áreas de intervenção - contrapõe os componentes positivos e negativos da gestão do exercício, relativos às áreas de intervenção nas quais articula-se o relatório social (e que pressupõe, portanto, a disponibilidade de um sistema de contabilidade econômico-analítica);

- Repartição do valor adicionado global - retoma a destinação do valor adicionado às diferentes categorias de stakeholders (remunerações direitas e indereitas ao pessoal; impostos e transferências em conta de exercício a favor da administração pública; interesses financeiros correspondentes aos fornecedores de capital) e a quota residual destinada à conservação e ao incremento do patrimônio.

As Linhas Guia do Observatório tentam uma aproximação diferente porque parte das críticas sobre significado do valor adicionado aplicado às AP e das entidades sem fins lucrativos em geral. Trata-se do problema de ordem metodológica inerente à quantificação e valorização daqueles outputs (produtos e serviços) que não geram operações de troca monetária. Como foi observado, "para a determinação do valor adicionado, portanto, falta um dos dois termos de comparação indispensável para a medida: o valor da produção" (Marcon, 2008). Nas administrações públicas, os valores positivos da produção são representados só em parte pelos proventos (tributos locais e as transferências de outras administrações). Portanto, o equilíbrio gerado representa um equilíbrio econômico, cujas condições são largamente exógenas. Uma margem residual, embora positiva, depois da remuneração dos fatores produtivos, pode esconder condições de ineficácia e de uma incoerente capacidade de satisfazer as necessidades, em termos de eficiência, dos destinatários atuais e futuros.

Não se deve esquecer que, enquanto o standard GBS é destinado para todas administrações públicas, as Linhas Guia do Observatório são dedicadas ao âmbito operacional específico das entidades locais. Depreende-se que:

- É pretensão do Observatório integrar o balanço social no âmbito do "sistema de prestação de contas" das entidades locais, numa relação de estrita complementaridade com os outros documentos nos quais se expressa o ciclo da programação, previsão, gestão, relatório, revisão econômico - financeira e controle interno, Bem como, em particular, com funções adicionais ao balanço consultivo (o "relatório"), ou seja, do documento destinado a fornecer informações ligadas à autuação dos programas, à situação 
patrimonial-financeira, ao andamento econômico e aos resultados socialmente relevantes produzidos pela administração;

- as Linha Guia consideram, pragmaticamente, o estado dos sistemas contábeis das entidades locais. Em particular, estes últimos são baseados ainda numa lógica financeira (cash) e de autorização (budgetary accounting). A reforma de 1995 introduziu a obrigação de inserir, no relatório de fim período, a conta econômica, mas não impôs às entidades a adoção dos sistemas contábeis de tipo econômico patrimonial (full accrual); assim como os sistemas de contabilidade econômicoanalítica não constituem, neste momento, uma prática difundida entre as administrações locais.

Portanto, as Linhas Guia orientam o balanço social para a direção de um relatório que seja coerente com sistemas contábeis que apresentem estas características. Na parte destinada a ilustrar os "recursos econômico-financeiros", o balanço social deve permitir ao leitor compreender:

- a entidade e a proveniência dos recursos financeiros a ela destinados no período do relatório;

- a situação relativa aos balanços e resultados de administração;

- a distribuição das despesas correntes e em conta capital entre as diferentes macroáreas de intervenção.

Um aspecto peculiar das Linhas Guia é que o relatório pode ser estendido também àqueles recursos que estão ligados com as atividades realizadas pela entidade no período de referência e que não transitam pelo balanço (como no caso de participação em projetos de terceiros pelos quais foram utilizados recursos públicos ou privados não geridos diretamente pela entidade). Para cada uma dessas atividades, a entidade relata: a macroárea de intervenção interessada, o programa ao qual se refere, a tipologia da atividade, os sujeitos participantes, a quantidade dos recursos ativados e que não transitaram pelo balanço.

Pode-se observar que no standard GBS, centrado no relatório do valor adicionado, a informação financeira não é ausente, mas colocada numa perspectiva especifica das entradas e saídas por áreas de intervenção, que têm ligação com os dados da contabilidade financeira.

As duas entidades reguladoras dão grande relevância ao relatório ligado ao patrimônio. 0 GBS prevê um esquema dedicado. A perspectiva informativa compreende o patrimônio e outros bens e empenhos. Ela integra dados de origem contábil com informações quantitativas e qualitativas de fontes extra contábeis e prevê o cálculo de alguns indicadores concernentes à gestão patrimonial. As Linhas Guia não estabelecem um esquema rígido de exposição dos dados. Todavia, existe uma ampla convergência entre as duas fontes acerca das finalidades e dos conteúdos da informação sobre o patrimônio. As informações divulgadas devem possibilitar a avaliação:

- Da dinâmica dos ativos, passivos e do patrimônio liquido, requisito satisfeito através da publicação de uma serie histórica de dados patrimoniais (ao menos trienais);

- Das finalidades públicas perseguidas através da gestão patrimonial e da congruência da dotação patrimonial com a missão declarada;

- Das principais operações de aquisição, baixa, reconversão e requalificação dos ativos, com indicações sobre as motivações, destinações dos recursos adquiridos e dos beneficiários; 
- Da destinação, estado de uso, modalidade de valorização e de fruição por parte da coletividade de referência dos bens de maior valor histórico, artístico, cultural e ambiental;

- Dos bens concedidos ao uso de terceiros (com as respectivas motivações e condições) e dos bens concedidos para utilização da entidade.

Aspectos particulares da informação referem-se às modalidades de capacidade do inventário (standard GBS), ao estado das manutenções e aos equilíbrios financeiros e patrimoniais a curto e longo prazos (Linhas Guia do Observatório). Esta ultima fonte assinala-se pelo pedido de representação separada pela perspectiva informativa do patrimônio consolidado do grupo público local.

\section{A RELAÇÃO SOCIAL E OS SERVIÇOS PARA ÁREAS DE INTERVENÇÃO}

Esta parte do balanço social constitui o "coração" do relatório, pois deve oferecer às diferentes categorias de stakeholders a avaliação dos resultados da administração e dos impactos gerados no território e na coletividade de referência.

0 ponto inicial é representado pela relação, em ordem de prioridade, das áreas de intervenção e dos principais stakeholders envolvidos em cada área, em conformidade com o que foi informado nas seções dedicadas à identificação da entidade (missão e estratégia) e aos informes econômico-financeiros por segmentos de atividade. 0 relatório, de fato, deve conter "objetos" mais analíticos relacionados ao contexto geral das atividades da entidade. Por outro lado, o reconhecimento das áreas de intervenção e dos stakeholders específicos não podem conflitar com os critérios subjetivos que se fundamentam no perfil estratégico e operacional da administração considerada. De fato, as áreas de intervenção são agregações significativas de atividades das entidades efetuadas, por exemplo, com base na homogeneidade dos resultados obtidos, dos destinatários principais da ação, das escolhas políticas, das unidades organizacionais responsáveis, das formas de gestão etc.

As duas fontes assinalam uma aproximação pragmática da individualização das áreas em foco no relatório.

O GBS sugere concentrar o relatório nas áreas "prioritárias", em relação à relevância inerente ao cumprimento da missão individualizada e das finalidades institucionais. Se algumas categorias significativas de stakeholders não resultem associadas às áreas prioritárias, a norma aconselha a "recuperação" como uma área específica do relatório.

As Linhas Guia para as entidades locais sugerem, ao contrário, uma aproximação gradual à individualização das áreas sobre as quais focar progressivamente o relatório, considerando a perspectiva de chegar, "a rigor", a um balanço que compreenda todos os aspectos em que se articula a atividade da entidade. Um ponto enfatizado nas Linhas Guia é a ligação entre as áreas utilizadas nos documentos de programação e, então, com programas e projetos individualizados no âmbito da programação de termo, trienal e anual, para limitar a "autoreferencialidade" do balanço social. E também, é requerido, para cada área, a indicação da situação inicial dos serviços, para permitir uma avaliação "comparativa" dos resultados obtidos.

Além das diferenças mencionadas, existe uma significativa convergência acerca dos conteúdos informativos requiridos por cada área objeto de relatório analítico. Eles tratam de:

- As finalidades e os objetivos perseguidos; 
- Os recursos utilizados;

- Os resultados obtidos;

Em particular, os recursos utilizados na área consideram aqueles internos à entidade (financeiros, econômicos e reais ou físicos) e aqueles mobilizadas por terceiros envolvidos nos processos de satisfação das necessidades públicas que se referem à administração considerada. Um aspeto relevante do relatório dos recursos, enfatizado no standard GBS, é a possibilidade de realizar avaliações comparativas relativas ao total dos recursos da entidade, por categorias de stakeholders, no sentido histórico (pela mesma administração pública) e espacial (entre administrações similares).

A avaliação dos resultados deve permitir, aos stakeholders interessados, um juízo sobre o nível de atingimento dos objetivos programados, expresso em termos qualitativos e quantitativos.

Sabe-se bem que a avaliação dos resultados das administrações públicas necessita a consideração conjunta de dimensões diferentes e complementares (eficiência, eficácia gerencial, eficácia ou impacto social) e deve fundamentar-se sobre a seleção de um conjunto de indicadores, contábeis e extracontábeis, coerentes com as finalidades das avaliações, significativos, claros, praticáveis, verificáveis pelos stakeholders, tempestivos e comparáveis 8 . 0 perfil qualitativo da avaliação deve incluir a modalidade de implementação dos programas e projetos, as críticas encontradas, as razões do não-cumprimento, total o parcial, dos objetivos programados.

Como foi observado, cada área do relatório deve destacar as categorias de stakeholders especificas, ou seja, os sujeitos para os quais as atividades são endereçadas de forma prioritária. A detalhada individualização dos stakeholders é fundamental para a construção do balanço social porque esses sujeitos não são simplesmente os destinatários, mas também atores do processo do relatório. 0 envolvimento dos interlocutores e as modalidades do envolvimento (também essas objeto do relatório) constituem, de fato, elementos essenciais para a adequação e eficácia do relatório.

Em particular, as Linhas Guia destacam a necessidade de que os envolvimentos aconteçam em três momentos distintos: a) na apresentação do projeto de elaboração do balanço social, através da obtenção de contribuições e identificação da disponibilidade dos stakeholders para a participação no processo de criação do relatório; b) no momento da apresentação, pelos relatores, da versão preliminar do relatório e dos indicadores propostos para mesurar o nível de realização dos objetivos, fase final para a coleta de solicitações e exigências dos interlocutores sociais; c) na divulgação dos resultados, quando os stakeholders são solicitados a expressar um juízo conclusivo (possível também através da compilação de questionários aplicados). Este juízo trata:

- da eficácia informativa do relatório;

- da avaliação dos resultados da administração;

- das observações e propostas para aperfeiçoamento da futura programação e relatório social.

Em síntese, a entidade promove formas de participação e coleta de comentários sobre o balanço social na fase de comunicação externa do documento definitivo aprovado, através encontros

\footnotetext{
${ }^{8}$ As diretrizes recomendam a publicação dos indicadores do exercício objeto do relatório e mais dois precedentes, bem como, se possível, comparativos com outras entidades similares.
} 
públicos, forum on line, pesquisas de opinião etc. Assim procedendo, o balanço social contribui para a integração e sustentação do processo de programação e controle da administração, estimula o aperfeiçoamento contínuo e orienta os conteúdos.

\section{DECLARAÇÕES FINAIS E ASSEVERAÇÃO}

A parte conclusiva do balanço social reúne algumas das mais significativas diferenças entre as duas entidades regulamentadoras.

Para o GBS, o documento se encerra com duas declarações sobre a governance da entidade relativas ao: a) juízo sobre os resultados obtidos e compromissos com melhorias de performance para exercício seguinte; b) empenho para a melhoria do processo do relatório social, com indicações operacionais.

Para o Observatório Italiano, o balanço social é concluído com uma asseveração que atesta a veracidade e a adequação das informações divulgadas, bem como a conformidade do processo do relatório com os padrões de referência adotados. A asseveração consta de um claro julgamento profissional acerca das informações incluídas no balanço social expresso pelo revisor independente, identificando: a) o órgão de revisão ao qual as entidades locais italianas estão ordinariamente subordinadas; b) o órgão de auditoria interna ou externa que efetuou o julgamento sobre a veracidade do balanço social apresentado, sobre a fidedignidade do processo de elaboração do documento e também sobre a relevância das informações prestadas.

\section{ALGUMAS EVIDÊNCIAS EMPÍRICAS}

Com o objetivo de evidenciar a relevância da aplicação e a propensão das administrações públicas para a escolha do modelo de redação do social reporting, no ano 2006, foi realizado um estudo sobre um padrão representativo de províncias italianas que adotaram os relatórios sociais ${ }^{9}$.

Tabela 3: Características do balanço social das províncias

\begin{tabular}{|l|c|c|c|c|}
\hline & $\begin{array}{c}\text { Analise por } \\
\text { stakeholders }\end{array}$ & $\begin{array}{c}\text { Presença de dados } \\
\text { econômicos, } \\
\text { financeiros e } \\
\text { patrimoniais }\end{array}$ & $\begin{array}{c}\text { Interpretação dos } \\
\text { dados contábeis por } \\
\text { stakeholders de } \\
\text { referência }\end{array}$ & $\begin{array}{c}\text { Análise segundo o } \\
\text { modelo do valor } \\
\text { adicionado }\end{array}$ \\
\hline Província de Cosenza & Sim & Sim & Sim & Não \\
\hline Província de Piacenza & Sim & Sim & Sim & Não \\
\hline Profíncia de Ravenna & Sim & Sim & Não & Não \\
\hline Profíncia de Livorno & Sim & Sim & Não & Não \\
\hline Profíncia de Genova & Sim & Sim & Sim & Não \\
\hline Profíncia de Parma & Sim & Sim &
\end{tabular}

\footnotetext{
9 Banco de dados sobre o relatório social elaborado pelo FORMEZ, Centro di formazione del Dipartimento della Funzione Pubblica della Presidenza del Consiglio dei Ministri, que oferece suporte e assistência às administrações públicas. 
Dentre as seis províncias observadas, nenhuma realizou o balanço através do critério do valor adicionado. A prática das províncias italianas aparece, portanto, alinhada com o modelo preposto pelo Observatório Italiano, em detrimento das propostas do GBS.

Com o objetivo de compreender a aplicação do modelo, a título de exemplo, decidiu-se apresentar, nos pontos mais relevantes, o caso da província de Cosenza ${ }^{10}$.

No balanço social, será apresentada uma série de relatórios que partem do exame do andamento das despesas correntes e dos investimentos no ano de 2006, subdividas por áreas de intervenção. Os resultados da entidade serão, portanto, expressos com referência às áreas prioritárias do relatório e comparativos com os dois exercícios precedentes.

É importante lembrar que as áreas do relatório são uma exigência do balanço social.

Depois da apresentação dos dados sócio-econômicos, o primeiro passo para o relatório dos resultados sociais consiste no reconhecimento das áreas de intervenção da ação pública e das categorias de todos os stakeholders envolvidos. Principalmente, é necessário definir o contexto de referência e os mecanismos através dos quais os stakeholders são envolvidos no processo decisório.

As áreas de intervenção são agregações significativas das atividades da entidade, efetuado em relação as homogeneidade dos objetivos adquiridos, dos destinatários principais da ação, das escolhas políticas, das unidades organizativas responsáveis, das formas de gestão, etc.

A individualização das áreas de intervenção tem que acontecer de forma coerente com a missão e a estratégia da entidade (especificadas na primeira seção do documento), bem como com os critérios de classificação dos valores financeiros, econômicos e patrimoniais (especificados na segunda seção do documento). Devem ser indicadas as categorias específicas dos stakeholders para cada área de intervenção.

É faculdade de cada entidade individualizar as áreas prioritárias em função das próprias escolhas estratégicas. No caso em questão (Província de Cosenza), foram individualizadas cinco macroáreas ${ }^{11}$ :

1. Serviços internos;

2. Serviços para a coletividade;

3. Economia, trabalho e formação profissional;

4. Território e ambiente

5. Patrimônio, edificação, transporte, acessibilidade e infra-estrutura.

Coerentemente com as Linhas Guia do Observatório, o relatório foi elaborado para cada macroárea.

Para facilitar a compreensão sobre a aplicação do modelo, optou-se, como exemplo, por apresentar e comentar a terceira macroárea: "Território e ambiente".

\footnotetext{
10 Balanço social do ano de 2006, referente à àrea da provincia de Cosenza.

${ }^{11}$ Em relação aos programas de ativação, os recursos são destinados para cada macroárea. 
O endereço de governo contém todos os programas e os projetos deliberados pela junta, as finalidades específicas e objetivos propostos, como também a individualização dos stakeholders de referência, recursos usados e empenhos futuros.

Tabela 4: Proposta de relatório para uma macroárea

\begin{tabular}{|c|c|c|}
\hline \multirow[t]{5}{*}{$\begin{array}{l}\text { Macroárea } \\
\text { individualizadada: } \\
\text { Território Ambiente }\end{array}$} & $\begin{array}{l}\text { Programas deliberados } \\
\text { pela Junta Comunal: }\end{array}$ & $\begin{array}{l}\text { 1)Desenvolver ações que visam a elevar a participação das } \\
\text { fontes de energia renováveis, } \\
\text { promover o desenvolvimento de ações de eficiência } \\
\text { energética em todos os setores (civil, } \\
\text { transporte, atividades econômicas etc.) } \\
2 \text { )............ } \\
\text { 3) } \\
\text { 4)......................... etc.; }\end{array}$ \\
\hline & Finalidade: & $\begin{array}{l}\text { 1)Sensibilização da opinião pública para o ganho de } \\
\text { eficiência energética nas habitações e nos edifícios } \\
\text { públicos; } \\
\text { 2)Gestão integrada dos ciclos (redução do uso das matérias } \\
\text { brutas) } \\
\text { 3)Reciclagem dos materiais e uso correto dos materiais de } \\
\text { construção presentes no contexto. } \\
\text { Etc...; }\end{array}$ \\
\hline & $\begin{array}{l}\text { Stakeholders } \\
\text { referência }\end{array}$ & $\begin{array}{l}\text { Stakeholders internos: } \\
\text { 1)setor técnico da entidade: edificação, economia, ambiente, } \\
\text { atividades produtivas, patrimônio etc. ... } \\
\text { Stakeholders externos: } \\
\text { 1)Comissão Européia; } \\
\text { 2)Ministério do Ambiente e da Tutela do Território; } \\
\text { 3)Região; } \\
\text { 4)Sociedades e empresas individuais; } \\
\text { 5)Sociedades municipalizadas; } \\
\text { 6)Entidades locais internas à província: comuns }\end{array}$ \\
\hline & Recursos utilizados & 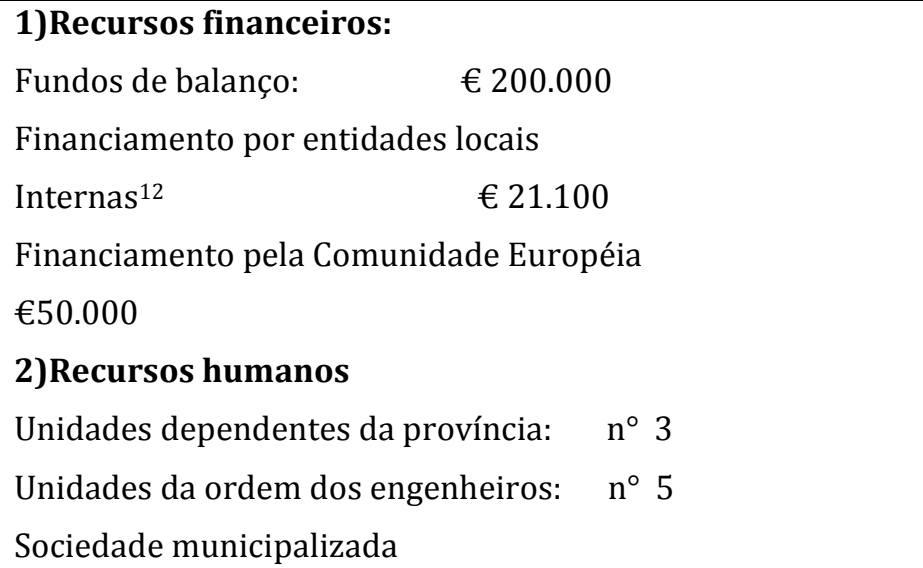 \\
\hline & Objetivos alcançados & $\begin{array}{l}\text { 1)Sensibilização da opinião pública sobre os princípios } \\
\text { fundamentais do desenvolvimento sustentável; } \\
\text { 2)Entidades e pessoas interessadas que usufruíram do }\end{array}$ \\
\hline
\end{tabular}

12 Entidades locais internas são as câmaras municipais de pertinência da província e as empresas públicas. 


\begin{tabular}{|l|l|l|}
\hline & & $\begin{array}{l}\text { projeto } \\
\text { 3)Resultado “midiático" }\end{array}$ \\
\cline { 2 - 4 } & $\begin{array}{l}\text { Atividades, Projetos e } \\
\text { empenhos futuros }{ }^{13}\end{array}$ & $\begin{array}{l}\text { 1)Continuar com as atividades de construção de uma } \\
\text { província ecológica; } \\
\text { 2)Enfrentar fenômenos degenerativos observados através } \\
\text { ações fortes de controle, tais como: criação de órgãos de } \\
\text { polícia } \\
\text { especializados; } \\
\text { 3)Instituição da fase de Certificação Energética dos } \\
\text { Edifícios de propriedades da entidade; } \\
\text { 4)Incentivar a construção de coletores solares térmicos e } \\
\text { fotovoltaicos. Etc. }\end{array}$ \\
\hline
\end{tabular}

As macroáreas de intervenção constituem o núcleo central do balanço social.

A segunda parte do relatório apresenta, em linhas gerais, os recursos disponíveis e utilizados, bem como sua proveniência e destino , numa ótica geral do relatório mediante a aplicação de indicadores de balanço.

Através o uso dos indicadores, portanto, pode-se chegar:

- à detalhada identificação e proveniência dos recursos financeiros;

- à sua distribuição por macroáreas;

- à contribuição que a macroárea oferece para o resultado econômico geral;

- ao equilíbrio e resultado financeiro do balanço.

É evidente, portanto, que o social reporting, pela obrigatoriedade de respeitar os requisitos de inteligibilidade e simplicidade, não pode desconsiderar os dados econômico-financeiros provenientes do balanço.

Na prática, a dimensão qualitativa prevalece sobre aquela quantitativa, mas esta última constitui elemento essencial e está ligada à seleção e cálculo dos indicadores (de eficiência e eficácia da gestão e social) coerentes com os objetivos indicados na fase de programação.

Concluindo, a relação contém, obviamente, informações sobre as dotações patrimoniais para Verificar, eventualmente, a variação do patrimônio decorrentes de alienações ou investimentos.

\section{CONCLUSÕES}

No contexto da administração pública italiana, o desenvolvimento das formas de relatório social ocorreu por dois motivos fundamentais: de um lado, pelo crescimento dos requisitos de accountability impostos às administrações públicas, no âmbito do processo de reforma administrativa italiana (processo denominado "aziendalizzazione da administração pública"); de outro, a incapacidade dos instrumentos contábeis tradicionais de atender ao crescimento da demanda de accountability. De fato, cabe destacar que os sistemas contábeis usados nas administrações públicas italianas ainda enfatizam os aspectos financeiros. 0 processo de evolução para modelos mais avançados (como a contabilidade econômico-patrimonial,

\footnotetext{
13 Pelo modelo proposto, deduz-se o papel de "instrumentação previsional” do balanço social (orçamento). Ele tem que prestar contas aos cidadãos sobre a atividade executada, mas, principalmente, sobre os compromissos e programas futuros. 
contabilidade gerencial etc...) enfrenta obstáculos normativos e se realiza através das "boas praticas" ainda irregularmente difundidas pelo território nacional, bem como entre varias tipologias de entidades. Por este motivo, alguns estudiosos relacionaram o desenvolvimento recente do relatório social ao fracasso da contabilidade financeira aplicada às entidades locais.

Por outro lado, não há duvida de que no setor púbico os valores financeiros manifestam limitações ainda mais severas que no setor privado, em termos de capacidade de representar o desempenho e os resultados da gestão. No campo público e das entidades sem fins lucrativos, o balanço social parece ser o relatório mais adequado. De fato, os problemas de uma administração pública a diferencia da empresa privada. Não basta divulgar as suas finalidades sociais, mas de representá-las de maneira satisfatória.

Os administradores públicos, pelo menos aqueles mais conectados com as oportunidades geradas pelas inovações, aproveitaram a possibilidade de usar o relatório como um instrumento de comunicação voluntária, considerado que ainda hoje não existe uma norma que torne obrigatório o balanço social ou os outros instrumentos do social reporting. Naturalmente, este feito põe imediatamente em evidência o problema da confiança e verificação das informações. Na administração pública italiana, a tendência para usar a comunicação institucional com a finalidade de referência política é intrínseca, como também a relevância conferida ao "efeito anúncio" para se alcançar o consenso de que o balanço social é um elemento característico da gestão pública (Borgonovi, 2002).

As duas entidades regulamentadoras italianas analisadas neste trabalho, como também as recomendações do Departamento da Função Pública do ano 2006, têm o mérito de fixar um primeiro núcleo de regras, embora de adoção voluntária, em matéria de balanço social.

As duas entidades regulamentadoras possuem abordagens metodológicas semelhantes para o tema. Elas, de fato, entendem o balanço social como tendo um duplo significado de "processo e produto".

Introduzir o balanço social na administração pública italiana significa, acima de tudo, construir um procedimento que seleciona, apanha e sintetiza informações socialmente relevantes, com o envolvimento dos sujeitos internos e externos à entidade. Destaca-se que os padrões estabelecidos individualizam a participação dos stakeholders envolvidos nas principais áreas de intervenção da administração, em vários momentos do processo, um requisito indispensável para a confiança e relevância do sistema de informação.

Ademais, progride a idéia de que o balanço social deve ser submetido à asseveração de um órgão de revisão interno (que já existe), mas também a uma verificação externa. Sobre isso, as Linhas Guia constituem um ponto de referência bem avançado.

Quanto aos conteúdos do "produto-balanço social", existem muitas semelhanças entre as indicações das entidades regulamentadoras. Em particular, as áreas de intervenção e os stakeholders envolvidos constituem as dimensões fundamentais de articulação do relatório.

As diferenças significativas entre as duas entidades regulamentadoras examinadas estão relacionadas com as informações econômico-financeiras e com a reclassificação dos dados contábeis. 0 padrão estabelecido pelo GBS mantém uma lógica parecida com a do relatório social das empresas e está alinhada aos modelos de balanço social consolidados em alguns paises europeus: o foco é representado pela formação e repartição do valor adicionado. As Linhas Guia elaboradas pelo Observatório para as entidades locais, ao contrário, omitem a informação sobre o valor adicionado, considerando uma quantidade não representativa do valor público criado, centrando o relatório sobre a reclassificação dos recursos financeiros (entradas e saídas) por 
área de intervenção. Esta escolha, desconsiderando o seu fundamento teórico, demonstra a intenção pragmática de integrar o relatório social à tipologia dos dados disponíveis, no contexto das administrações locais, como produtos dos sistemas contábeis utilizados.

Os aspectos aqui analisados não esgotam o tema. Outros elementos compõem a sua complexidade e podem orientar diferentes experimentações práticas, gerando estúdios futuros sobre o relatório social aplicado à administração pública.

\section{REFERENCIAS BIBLIOGRÁFICAS}

ANSELMI, L. (1995). Il processo di trasformazione delle pubbliche amministrazioni. Il percorso aziendale. Torino: Giappichelli.

BORGONOVI, E. (2002). Principi e sistemi aziendali. Milano: Egea.

BORGONOVI, E. (2000). Principi e sistemi aziendali per le amministrazioni pubbliche. Milano: Egea.

CODA, V. (1988). L'orientamento strategico d'impresa. Torino: Utet.

D'AMORE, M. (2008). The Harmonization of Government Accounting and the Role of IPSAS. Milano: McGraw-Hill.

GBS. (2007). Il Bilancio Sociale - Standanrd - La Rendicontazione Sociale nel Settore Pubblico. Milano: Giuffrè.

HINNA, L. (2004). L'evoluzione dei bilanci sociali nelle imprese e nelle pubbliche amministrazione., (p. Tavola Rotonda: l'evoluzione dei bilanci sociali nelle imprese e nelle P.A.). Roma.

MARCON, G. (2008). Significatività dell'informazione contabile nel Bilancio Sociale delle Aziende Pubbliche. Azienda Pubblica , 207.

MASINI, C. (1979). Lavoro e risparmio. Torino: Utet.

MATACENA, A. (1984). Impresa ed ambiente. Il bilancio sociale. Bologna: Clueb.

MOORE.M. (1995). Creating Public Value, Harvard University Press.

POZZOLI, S. (2006). Bilancio Sociale versus Bilancio legale. Azienditalia , 182.

VALOTTI, G. (2000). La riforma delle autonomie locali. Dal sistema all'azienda. Milano: Egea.

VIVIANI, M. (1999). Specchio magico. Bologna: Il Mulino.

ZAPPA, G. (1957). Le produzioni nell'economia delle imprese. Milano: Giuffrè. 